Citation:

Sahin, 0. Stewart, R.A. Giurco, D. Porter, D.G. (2016) Renewable hydropower generation as a co-benefit of balanced urban water portfolio management and flood risk mitigation. Renewable and Sustainable Energy Reviews, http://dx.doi.org/10.1016/j.rser . 2016.01.126.

http://WWW. sciencedirect.com/science/article/pii/S1364032116001817

\title{
Renewable hydropower generation as a co-benefit of balanced urban water portfolio management and flood risk mitigation
}

\section{Authors}

Dr. Oz Sahin

Griffith School of Engineering, and

Griffith Climate Change Response Program

Griffith University, Qld 4222 - Australia

Phone : + 61755527378

E-mail : o.sahin@griffith.edu.au

Professor Rodney A. Stewart (Corresponding author)

Griffith School of Engineering,

Griffith University, Qld 4222 - Australia

Phone : +61 755528778

E-mail : r.stewart@griffith.edu.au

Professor Damien Giurco

Institute for Sustainable Futures

University of Technology Sydney, NSW - Australia

Phone : +61 295144973

E-mail : damien.giurco@uts.edu.au

Professor Michael G. Porter

Centre for Regional and Rural Futures,

Faculty of Science, Engineering and Built Environment

Deakin University, Melbourne Victoria

Phone : +61 352278424

E-mail : michael.porter@deakin.edu.au 


\title{
Renewable hydropower generation as a co-benefit of balanced urban water portfolio management and flood risk mitigation
}

\author{
Oz Sahin ${ }^{1}$, Rodney A. Stewart*1 ${ }^{1}$ Damien Giurco ${ }^{2}$, Michael Porter ${ }^{3}$ \\ ${ }^{1}$ Griffith School of Engineering, Griffith University, Australia \\ ${ }^{2}$ University of Technology Sydney, Institute for Sustainable Futures, Australia \\ ${ }^{3}$ Centre for Economics and Financial Econometrics Research, Deakin University, Australia \\ *Corresponding author. Email: r.stewart@griffith.edu.au,Phone: +61 0755528778 \\ Postal address: Griffith School of Engineering, Griffith University, QLD 4222, Australia.
}

\begin{abstract}
:
Understanding energy-water system interactions is critical to the effective management of urban infrastructure. This paper explores the potential for hydropower as a co-benefit in a novel operating regime for Sydney’s main water reservoir (Warragamba Dam). Hydropower could be generated as part of storage level management in the reservoir aimed at introducing flood retention 'airspace' (to mitigate downstream flood risk from extreme rainfall) whilst augmenting the use of installed desalination capacity to maintain secure supplies of water. A purpose-built systems dynamics model provides the mechanism for evaluating and comparing future operating scenarios over a 25 year period (i.e. until 2040). Importantly, the findings reveal the potential for desalination plants, integrated into a populous city's water supply network, to satisfy a much broader planning agenda. Specifically, the study provides evidence that Sydney's interdependent goals of deferring capital intensive flood storage works, maintaining water security, better utilising existing desalination and hydropower assets, and increasing renewable energy generation can be achieved through applying systems thinking to a complex citywide water planning problem. The work also makes a valuable contribution to the energy-water nexus literature at the under-explored city-scale.
\end{abstract}

Keywords: Renewable energy; hydropower; flood mitigation; desalination; urban water portfolio management; systems dynamics modelling. 


\section{Introduction}

The need to jointly consider the energy-water nexus is increasingly acknowledged $[1,2]$. Infrastructure for providing energy and water in global cities such as Sydney, Australia, are changing and this makes the development of approaches to understand the dynamics of the water-energy nexus even more pressing. In the case of energy, smaller scale generation from sources such as hydropower, wind, solar and onsite cogeneration plants are challenging the historical dominance of centralised large scale generation. In short, the development of a decentralised, distributed energy landscape is underway [3]. In a context of supplying a growing city population whilst maintaining healthy river flows, factors such as climate change which affects patterns of rainfall, runoff and drought, collectively put pressure on water utilities to assess realistically the capability of existing water systems and the investment required to meet future needs. The ability to manage both water shortages during drought and floods arising from extreme weather becomes paramount. In Sydney, as in other major coastal cities, the need to confront drought has resulted in water supplies from surface and ground water being supplemented by sea-water desalination and recycled water, yet severe flood risk remains hitherto unmitigated. Having a diverse portfolio of water supplies necessitates an adaptive planning approach to water management, seeking new system optimisation opportunities in light of new information, such as the integration of hydropower utilisation into dam management strategies which can also contribute to mitigating flood risk.

Overall, a key challenge, is thus to improve modelling and planning approaches to take account for important energy-water interactions relating to urban infrastructure, consistent with adaptive planning. These energy-water interactions may span the use of water in hydropower and water heating systems [4, 5], to understanding the energy-intensity of rainwater harvesting systems $[2,6]$, to managing the energy intensity of diversified water supply and recycling options [7] to the use of energy in desalination plants for urban water [8].

In the context of urban water supply, energy interactions related to the energy-water nexus vary across spatial scales. In Australia, these can range from (i) the household scale, such as the additional pumping energy where rain tanks are used in detached dwellings for irrigation and toilet flushing in addition to centrally reticulated water supplies; (ii) to the urban precinct scale, where a group of apartments may have a common on-site water recycling system; (iii) to the city scale where desalination has become popular in major cities over the last decade to supplement surface and ground water supplies to ensure security in times of drought. 
Water-energy interactions related to (i) have been studied in detail $[2,9,10]$ and led to the reduction of energy usage through better pump and rain tank system design. With respect to item (ii) studies have focused on the use of renewable energy, water harvesting and recycling to make residential precinct developments 'net positive' or exporting of energy and water [11]. However, with respect to the larger scale city-wide analysis of the water-energy nexus, namely (iii), research has largely been confined to assessments on the extent to which desalination would raise the average energy intensity of water delivery per $\mathrm{m}^{3}$ in the city's water supply [12].

Nonetheless, while desalination technology is acknowledged as having a higher energyintensity than traditional surface water sources of water supply and currently often sit idle in times of abundant water supply, these assets can be better utilised to simultaneously address complex long-term water security, peak energy generation and flood risk management issues facing a city's planners. Such a complex planning problem is being faced by Sydney, which has the dilemma of better utilising a recently constructed desalination asset with ongoing cost obligations, public pressure to provide flood storage 'airspace' for the Warragamba dam, and heightened expectation to integrate more renewable energy sources into their electricity generation portfolio.

\section{Contextual framework}

\subsection{Water security and flood risk}

To what extent the water resources can meet the needs of a growing population is hotly debated, especially during the dry season as experienced in the Millennium Drought between 1997 and 2009, the worst in recorded history in Australia [13, 14]. At its peak, five state governments sought to augment water supplies via implementing significant infrastructure programs to secure urban water supplies. As a result, six seawater desalination plants have been built to augment bulk water supplies for the five major Australian cities. These infrastructure investments represent a total capital expenditure in excess of AUD\$12 billion (Table 1). As shown in Table 1, most of these desalination plants are currently on standby / mothballed.

In Sydney, the Metropolitan Water Plans 2010 (MWP) [15] introduced a more diverse water management portfolio including dams, recycling, water efficiency measures, and desalination plants. A desalination plant as a drought security water supply system was constructed in the Sydney region at a cost of AUD\$1.8billion. Under the MWP operating rules, existing 
desalination plants operate at maximum capacity when available dam storages fall below $70 \%$ and continue to do so until storages reach $80 \%$ [16]. That is, the plant has flexibility to operate at different levels. Through these rules, the water utility in Sydney aims to achieve the following goals: a) reducing the likelihood or severity of drought restrictions; b) reducing the probability of having to further supplement the water supply system; c) providing increased water security; and d) maintaining environmental flows for river health.

Table 1. Main Australian desalination plants and their respective costs, energy use and water production capacities [17-19]

\begin{tabular}{lccc}
\hline Location & $\begin{array}{c}\text { Completion } \\
\text { date }\end{array}$ & $\begin{array}{c}\text { Cost } \\
\left(10^{6} \text { AUD } \$\right)\end{array}$ & $\begin{array}{c}\text { Capacity } \\
\left(10^{6} \mathrm{~m}^{3} / \text { year }\right)\end{array}$ \\
\hline Adelaide & 2012 & 1,830 & 100 \\
Gold Coast & 2009 & 1,200 & 49 \\
Melbourne & 2012 & 5,700 & 150 \\
Perth-I & 2006 & 387 & 45 \\
Perth-II & 2012 & 1,400 & 100 \\
Sydney & 2010 & 1,890 & 90 \\
\hline Total & & 12,407 & 534 \\
\hline
\end{tabular}

According to Sydney's current operations plan, after exhausting various other supply augmentation and demand measures (e.g. desalination plant and pumping water from other rivers, reservoirs and temporary ground-water storages, and water restrictions), the decision for construction of a second desalination plant will be triggered when total dam storage levels drop to 30\% [20]. The costs and benefits of different operating regimes for the desalination plant were assessed by the Centre for International Economics (CIE). The CIE reported that the desalination plant can be very effective if it is used when dam storages are still relatively high. This allows the plant to generate a buffer of water in the dams that can be used to satisfy the water demand during dry periods [21]. However, if desalination is utilised only when dam levels are very low, e.g. 30\% or less in a deep drought, this will reduce effectiveness in a drought, when dam levels fall further. Broader use of desalination augmentation may then avoid the need to introduce severe water restrictions or other extreme drought measures. However, the energy used in the desalination process is primarily electricity and heat. To avoid generating large amounts of greenhouse gasses from desalination due to the high energy requirements, in Sydney the desalination plant is powered by renewable energy. More broadly, the major impediment with desalination has been its high energy consumption [8]. However in optimising a water supply system which includes 
both desalination and dams, the role of dam-fed hydropower should also be considered, for its role (even though intermittent and at smaller scale) in providing renewable energy.

\subsection{Hydropower potential in managing peak electricity demand}

The development and use of sustainable and environmentally friendly energy sources are critical to address global energy shortages and to reduce the reliance on fossil fuel [22]. Hydropower is a globally important renewable and low-emissions source of energy, where rivers permit. Hydropower is in fact the most common and oldest source of electricity, generated through capture of the kinetic energy in fast flowing water. In addition, depending on water availability, hydro power can be generated or ceased at the flick of a switch. Consequently, hydroelectric plants can profitably and efficiently provide peak power supply thanks to its storage capacity and fast response characteristics. Hydro power is thus especially suited to managing fluctuations in electricity demand and dampening frequency volatility, as residential and non-residential use of electricity shifts.

In terms of levels of water impoundment, there are three main hydropower types, namely: run-of-river, reservoir (storage hydro) and pumped storage. Based on the level of the installed electricity capacity, hydropower plants are classified as small-scale and large-scale hydropower systems [23].

The share of hydropower in total primary energy consumption is only $2.3 \%$ globally and 0.8 $\%$ in Australia [24]. Australia has already developed much of its large scale potential hydro energy potential. As of 2010, hydroelectricity accounted for 5.5\% of Australia's total electricity output, but much more in value terms. In terms of large scale power generation, hydro is well established compared with the relatively younger generation renewables of solar, bioenergy, wind and wave power [25]. Although hydroelectricity currently accounts for the largest share of Australia's renewable electricity, potential for future development is limited due to unreliable water availability. For example, electricity generation from hydro has declined in recent years because of an extended period of drought in eastern Australia, where most hydroelectricity capacity is located [24]. Many consider development of small scale hydro plants (relative to the Snowy and Tasmania) and improved efficiency of large scale hydro plants as the most likely path to future growth in Australia's hydroelectricity generation. In addition, utilising hydropower from other dams (e.g.: retrofitting old dams with turbines and connecting to the power grid) could contribute to the amount of renewable energy available across the country. Moreover, to increase the economic appeal of small- 
hydro power plants, and hence to favour their further deployment, innovative management strategies have been proposed to increase plant life time and operating range, and for maximising the profitability when significant inflow and market fluctuations occur [26].

In Sydney, the Warragamba hydroelectric plant was designed as an integral part of the dam to supply $50 \mathrm{MW}$ into the State electricity grid using surplus water (approximately $58 \mathrm{~m}^{3} / \mathrm{s}$ ) [27]. Currently, the existing mid-scale (50 MW) storage hydroelectric plant operates only when there is a high water level in the lake (e.g.: during discharge of large volumes of water). Effective use of water infrastructure and resources is a challenging problem. By installing additional electricity generation equipment at this dam, or modifying the operating rules of the existing plant, the hydropower industry in Sydney can tap the waters already flowing through this existing infrastructure. Retrofitting/modifying this dam expands the supply of renewable energy and helps maximises the benefits of existing infrastructure, while continuing to maintain water security.

\subsection{Research focus and objectives}

By considering the climate change challenge, nations across the world have been developing different scenarios economy wide or in different sectors in order to retain economic growth and to reduce the level of greenhouse gases emissions, simultaneously [28]. Accordingly, in the face of changing climate, highly variable rainfall patterns, population growth and environmental issues, the biggest challenge for the water utilities is to make socially, environmentally and economically viable decisions on the timing, the size, and the operation of the water infrastructure investments without compromising water security. This is a complex optimisation problem of searching and finding the best solution from all practical solutions

This paper adopts a more nuanced systems approach to modelling the energy-water interactions by looking at the role of dam-based small hydro as part of an optimisation relating to the dynamic changing of the level of water held in the dam. The overall optimisation uses both desalination supply capacity and dam water storage and 'airspace' to meet three core objectives, namely: (i) secure the city's water supply; (ii) mitigate flood risk beyond the dam should a heavy rainfall event occur, by leaving sufficient air-space in the dam storage; and (iii) explore hydropower potential during periods of water abundance and release from the dam in order to maintain a sufficient flood storage buffer. The case study to 
demonstrate this approach is centred on the densely populated of Sydney, located in the State of New South Wales in Australia.

\section{Approach}

Typically, water resources systems are characterised by multiple interdependent components that together produce multiple economic, environmental, ecological and social impacts [29]. Thus, water utilities working to improve the performance of these complex systems must identify and evaluate alternative supply design and management strategies, which are defined by the values of numerous decision variables.

However, developing appropriate response strategies is a difficult process due especially to the uncertainties in future projections of rainfall and climate variability. For example, damaging drought, or flooding, can come in many different magnitudes and duration, and may be devastating if they are not managed well. The extent of drought (or flooding) can rarely be predicted with any precision or prevented, but plans can be made to proactively mitigate their consequences. Preparing under substantial uncertainty requires some prediction techniques, foresight, initiative, flexibility and luck in order to proactively adapt to changes.

Simulation modelling is an effective method for evaluating the management of region or citywide water supply systems as well as for exploring the interrelated impacts of various supply and demand management including pricing options that are being used now or considered for the future. Models enable quantitative prediction the values of the target or decision variables under a range of scenarios. Their outputs are based on structural models and assumptions re variables over time, their interdependencies and particularly the previous time-series inputs which reflect prior values of the system being simulated. Even if these assumptions and input data reflect, or are at least representative of, conditions believed to be true, we know they will be inaccurate. Modelling is simplification and allows predictions only within confidence bounds. The model should be able to interpolate within the available knowledge base to provide a fairly precise estimate by using historical databases to simulate the past conditions with new data on similar inputs. [29].

\subsection{Systems approach}

The System Dynamics Modelling (SDM) approach used in this study provides a robust platform for analysing the interactions between variables influencing water demand and supply, and for exploring the sensitivity of the results to the economic, social and 
environmental assumptions. It is a powerful tool for informing policy-makers seeking to undertake long term planning of water supply augmentation decisions and has been used for long term planning in a range of fields [14, 30-32].

Strength of this modelling approach is that the sensitivity of the model to the baseline assumptions can be explored, such as desalination plant size, trigger level for desalination operating rules, and critical dam levels for new desalination investment decision. Further, this modelling approach incorporating sensitivity analysis ensures that more informed water infrastructure decisions are made in the context of long term water planning with changing weather patterns.

In this context, to build the model and raise the shared level of understanding, we have worked with assumptions regarding parameters and responses drawn from a range of experts from academia, private consulting firms and government water agencies, in order to produce a logical simulation model that attempts to explain the key elements of the Sydney water supply system. The system diagram used in this paper for analysing research questions/objectives is presented in Fig.1. System diagrams (or conceptual models) are important tools in systems analysis.

A system diagram represents cause - effect relations between elements or sub-systems of the overall system [29]. These components form feedback loops that are linked with other feedback loops. Feedback is a process whereby an initial cause ripples through a chain of causation and interdependence, ultimately to re-affect itself [33]. The SDM (Fig.1), using the Vensim ${ }^{\circledR}$ DSS [34], was built by identifying key variables, estimating assumed relationships between these variables and finally parameterising these relationships. The Vensim software family includes several configurations suitable for different levels of modelling needs. Vensim ${ }^{\circledR}$ DSS configuration is for professional utilisation and is suitable for managing large and complicated models by providing a range of built-in tools including Causal Tracing ${ }^{\mathrm{TM}}$ of a systems' structure and behaviour, Monte Carlo sensitivity, optimisation and array capabilities.

The SDM was first developed and applied in South East Queensland, Australia to explore scarcity pricing [14] and potential of pressure retarded osmosis (PRO) technology to generate electricity [31]. It was subsequently modified for Melbourne [30, 32] to explore rain independent desalination versus more traditional rain dependent dams in long term planning. Further details of the model can be found in these papers [14, 30-32]. Based on these 
previous studies, the generalised model has been customised for optimising the long-term water supply system in Sydney by considering the energy dimension and competing goals of water security and flood risk. Fig. 1 illustrates the urban water supply and demand submodel, while Fig. 2 illustrates the Hydropower sub-model. In building the SDM, a participatory modelling approach was employed. Participatory model development can focus on portraying system structure, while model simulations reveal system behaviour, which is less intuitive and often the source of confusion [35-37]. The SDM is composed of three interconnected sub-models, namely: (i) Supply \& Demand sub-model; (ii) Asset management (risk trade-offs and economic analyses) sub-model; and (iii) Hydropower sub-model to create a more holistic representation of the coupled socio-environmental system, as illustrated in Fig.1.

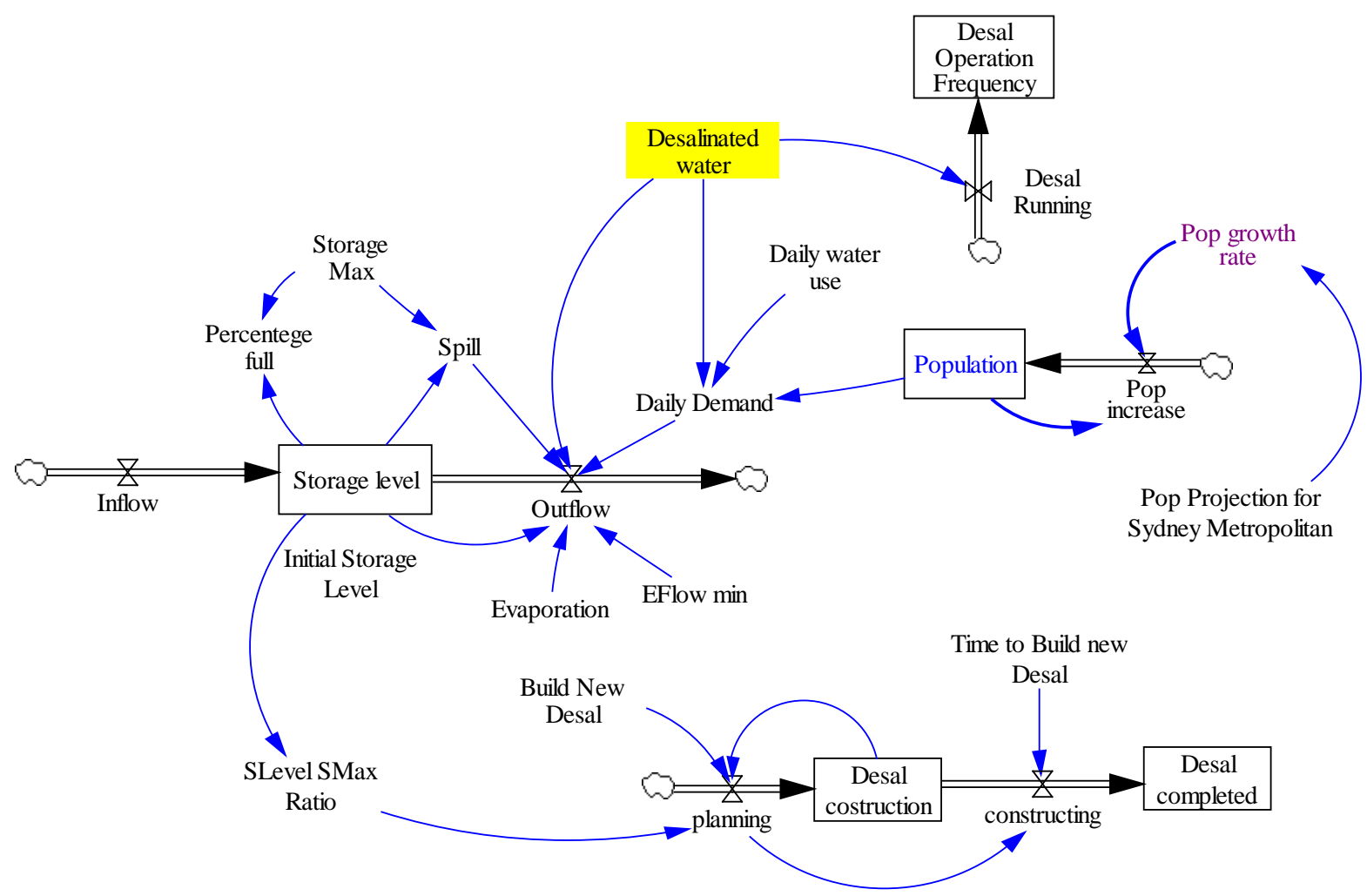

Fig. 1. A simplified System Dynamics diagram showing key variables and their causal relations and their causal relations

Fig. 1 shows the Supply-Demand sub-model capturing the supply, demand, population growth, new infrastructure decision and construction augmentations needed. It also illustrates the impacts of desalination plants on water supply as there is a strong interdependency between these categories, and it is, therefore, important to coordinate these interdependencies effectively within a modelling framework. The sub-model considers volumetric supply from 
both rain-dependent (dam) and rain-independent sources of water (desalination). A special feature of this sub-model is that it has an optional function where it can trigger the planning, design and construction of new augmented rain-independent supply sources to the bulk supply portfolio, when rain-dependent supplies are at critical threshold levels under the MWP operating rules [15]. Moreover, this sub-model is able to switch the existing portfolio of rainindependent supply sources to different operating capacities or even standby when surface water supplies are plentiful. For example, when surface storage capacity is above $70 \%$, rainindependent supply sources are placed on standby to reduce the supply cost. When the storage level drops below a 70\% level, then this supply become active and adds water to the grid. The demand is function of the population and the per capita water use. The reservoir storage level is driven by the inflow and the outflow variable.

For the purposes of this paper, asset management encapsulates both the financial interactions influencing the management of water infrastructure, and the operating procedures that determine the utilisation of this infrastructure. Using the Asset management sub-model of the SDM, the authors explored options for raising the dam wall to offer airspace or storage volume to assist flood mitigation, and have contrasted this option with an alternative option, namely to lower the full storage level in the current dam and utilise idle desalination capacity to support water security with lower dam capacity. To examine whether the utilisation of desalination plants are a viable option for covering the lost supply capacity from a decision to reduce the full supply level (FSL) to allow some flood mitigation airspace in the existing dam, a series of options have been explored for a projection period of the next 25 years (2015 to 2040). Further, the effectiveness of the current Metropolitan Water Plan (MWP) operating rules (i.e. desalination plants operate at maximum capacity when available dam storages fall below $70 \%$ and continue to do so until storages reach $80 \%$ ) were tested whether they would provide effective water security under extreme conditions. The hydropower sub-model linked to these two sub-models is explained in the section 3.4

\subsection{Systems boundary: Key assumptions and variables}

System boundaries are important in identifying the key model input variables as well as deciding their interdependencies. Key variables required for the herein developed SDM were identified through a comprehensive literature review, expert consultations, and workshops with experts, water utilities and researchers (Table 2). The constituents used in SDM are mainly classified into flow variables, rate variables, constants, auxiliary variables and table functions. Spatial boundaries of the SD comply with the boundaries of the grid connected 
Warragamba dam in Sydney water supply system. The stock levels and asset values, such as dam volumes and capital values are determined from the modelled and assumed flows and investments per period, adjusting prior levels including through evaporation, leakage and depreciation.

The population estimate of 4.28 million is based on NSW Government's population projections data [38]. Population growth rates were used based on detailed projections from the NSW Government report and ranged as follows: $1.66 \%, 1.67 \%, 1.53 \%, 1.39 \%$ and $1.25 \%$ for the each five year period of 2016-21, 2021-26, 2026-31, 2032-2036 and 2037-41. Based on historical usage patterns, water use is assumed to be 300 litres per person per day including residential use and non-residential use [39]. Raw historical inflow, spillage and extreme event datasets were obtained from the Sydney Catchment Authority, and refined to improve the quality of data.

Table 2. Key input values and assumptions for Sydney water system

\begin{tabular}{|c|c|}
\hline Input & Input values \\
\hline Population in 2014 (Persons) [38] & $4.28 \times 10^{6}$ \\
\hline Population growth rate (\%) [38] & $\begin{array}{l}\text { Varying from } 0 \text { to } 2.5 \\
\text { Default }=1.25 \%\end{array}$ \\
\hline Current water use per capita (L/d) [39] & $\begin{array}{l}300 \\
\text { (residential and non-residential) }\end{array}$ \\
\hline \multicolumn{2}{|l|}{ Warragamba dam [40] } \\
\hline Existing capacity $\left(\mathrm{hm}^{3}\right)$ & 2,027 \\
\hline Height (m) & 142 \\
\hline Hydropower capacity (MW) & 50 \\
\hline Desalination capacity $\left(\mathrm{m}^{3} / \mathrm{d}\right)$ [16] & 250,000 \\
\hline Desalination capital costs ( $\$$ Billion) [41] & $\begin{array}{l}1-3^{1} \\
\text { Default }=1.2^{1}\end{array}$ \\
\hline Desalination operation costs $\left(\$ / \mathrm{m}^{3}\right)$ & $\begin{array}{l}\text { Varying from } 0.75 \text { to } 2.5 \\
\text { Default value: } 0.95\end{array}$ \\
\hline Model time bound (Year) & 25 \\
\hline Desal operating rules ${ }^{2}[16]$ & $\begin{array}{l}60 / 70 ; 70 / 80 ; 80 / 90 \% \\
\text { Default value }=70 / 80 \%\end{array}$ \\
\hline Time interval of simulation & $\begin{array}{l}1 \text { day for modelling flood risk } \\
\text { and } \\
1 \text { year for economic analysis }\end{array}$ \\
\hline Social discount rate $\%[14,32]$ & $\begin{array}{l}\text { Varying from } 1.5 \text { to } 5.5 \\
\text { Default value }=3.5\end{array}$ \\
\hline Size of new desalination $\left(\mathrm{m}^{3} / \mathrm{d}\right)$ & $\begin{array}{l}\text { From } 125,000 \text { to } 375,000 \\
\text { Default value }=250,000\end{array}$ \\
\hline
\end{tabular}

Notes: ${ }^{1}$ Australian dollars (0.9685 USD $=1.0$ AUD average for 2013 prices); ${ }^{2}$ Current desal plant operates at maximum capacity when available dam storages fall below $70 \%$ and continue to do so until storages reach $80 \%$. 
The capital cost of building desalination plants is assumed to range from AUD\$1.2-\$3.0 billion dollars (base year: 2013) depending on plant capacity varying from 125,000 $\mathrm{m}^{3} / \mathrm{d}$ to $375,000 \mathrm{~m}^{3} / \mathrm{d}$. For a $250,000 \mathrm{~m} 3 / \mathrm{d}$ plant (equal to the current Sydney desalination plant), the cost is assumed to be AUD\$1.5 billion based on recent desalination investment costs in Australia [41]. Operating costs for desalinated water also vary across Australia depending on the extent to which water is sourced from desalination is used in the water portfolio [42] and the respective assumed or actual energy costs. To calculate and compare the discounted cost of infrastructure investments and operation costs, the default discount rate was assumed to be 3.5, which is consistent with the variance in the rates used for long term analysis of climate policies [32, 43].

The storage level at the Warragamba is a function of the inflow and the outflow variables. One way of mimicking the randomness of a real world event is to use the historical data as the input values for the simulation model. The main advantage of historical data is realism. Thus, simulations based on historical data can more adequately and realistically answer the "what if' questions (e.g. what if the dam runs out of the water due to insufficient inflow, or what if the dam overflows due to extreme level of inflow). Therefore, the last 53 years of historical inflow data collected between 1961 and 2013 has been used to calculate the storage level at the Warragamba dam. The weather patterns during this period include extreme flooding and extreme drought periods. Therefore, this data reasonably represents stress scenarios based on real situations that occurred in the past, and provides a realistic foundation for simulating extreme conditions. Needless to say that historical data is rich enough to contain a reasonable representation of possible fluctuations in weather patterns.

The Outflow is a function of per capita water use (residential and non-residential), evaporation, environmental flow and spillage when the storage level exceeds the dam capacity. The assumptions and data sources for these variables are detailed in Table 2.

\subsection{Dealing with uncertainty: Sensitivity and scenario analysis}

A key intention of model development was to allow flexibility in assumed parameters, options and system management, rather than limit users to predefined scenarios. The SDM is capable of simulating a very large number of permutations, based on user choice and the multivariate Monte Carlo simulation technique, which is widely used for completing sensitivity analyses that are commonly applied in risk assessments under uncertainty over 
time. Therefore, rather than limiting the users to a set of predefined scenarios, a flexible scenario development approach has been employed, which enables users to modify key variables to accurately assess solution and thus policy alternatives by applying various scenario parameters (Table 2 and Table 3).

Based on these scenarios, over a 25 year time frame, the average storage level, the number of additional desalination investments needed to provide water security, the number of years that desalination plants take to become operational, the number of years storage level falls below critical level (40\%), and the discounted cost of desalination investment were all simulated. In addition, a sensitivity analysis for the average storage level (water security) was conducted to illustrate graphically the consequences of alternative assumptions about the future.

These include changing three key variables systematically:

1. The new desalination plant capacity $\left(125,000-375,000 \mathrm{~m}^{3} / \mathrm{d}\right)$;

2. the threshold for new desalination plant construction commencement decision (30$50 \%)$; and

3. the threshold demand/capacity ratios for desalination plant(s) to become operational (60-80\%).

Since sensitivity analysis, for even a modest number of parameters, will generate a large number of simulation results, we performed the 'Latin Grid' search approach, which ignored the numbered of simulations specified. This method has enabled an adequate number of simulations to examine every possible combination of parameters (see Table 3).

Table 3. Key variable parameters for Monte Carlo simulation scenarios

\begin{tabular}{lccc}
\hline Scenarios & $\begin{array}{c}\text { New desalination } \\
\text { plant capacity }\left(\mathrm{m}^{3} / \mathrm{d}\right)\end{array}$ & $\begin{array}{c}\text { Threshold for new } \\
\text { desal construction } \\
\text { decision }(\%)\end{array}$ & $\begin{array}{c}\text { Threshold for desal } \\
\text { to become } \\
\text { operational (\%) }\end{array}$ \\
\hline Scn01-21 & 125 & $\begin{array}{c}30-50 \\
\text { increment } 5\end{array}$ & $60-80$ \\
Scn22-42 & 250 & $30-50$ & increment 5 \\
Scn43-63 & 375 & increment 5 & $60-80$ \\
& & $30-50$ & increment 5 \\
& increment 5 & $60-80$ \\
\hline
\end{tabular}




\subsection{Better utilising existing infrastructure through renewable energy generation}

The above analysis examines infrastructure utilisation between the current desalination plant and dam to consider the dual objectives of water security and flood mitigation. A complementary benefit of this exercise is the generation of renewable energy, namely hydropower. Fig. 2 illustrates the System Dynamics sub-model used to simulate hydroelectricity potential at Warragamba dam over a 25 year period. Consistent with previous studies ([44, 45]), the following formula was used to calculate the potential hydropower generation at Warragamba dam:

$$
P=\eta \rho g Q H
$$

Where: $P$ is the mechanical power measured in Watts, $\eta$ is the generating efficiency, $\rho$ is the density of water $(\mathrm{kg} / \mathrm{m} 3), g$ is the acceleration due to gravity $\left(\mathrm{m} / \mathrm{s}^{2}\right), Q$ is the volume flow rate passing through the turbine $\left(\mathrm{m}^{3} / \mathrm{s}\right)$, and $H$ is the effective pressure head of water for hydropower generation $(m)$.

For a typical hydro system, the turbine efficiencies range from 80 to over $90 \%$ and this will reduce with size [44]. Accordingly, the turbine efficiency is assumed to be 0.85 in this assessment.

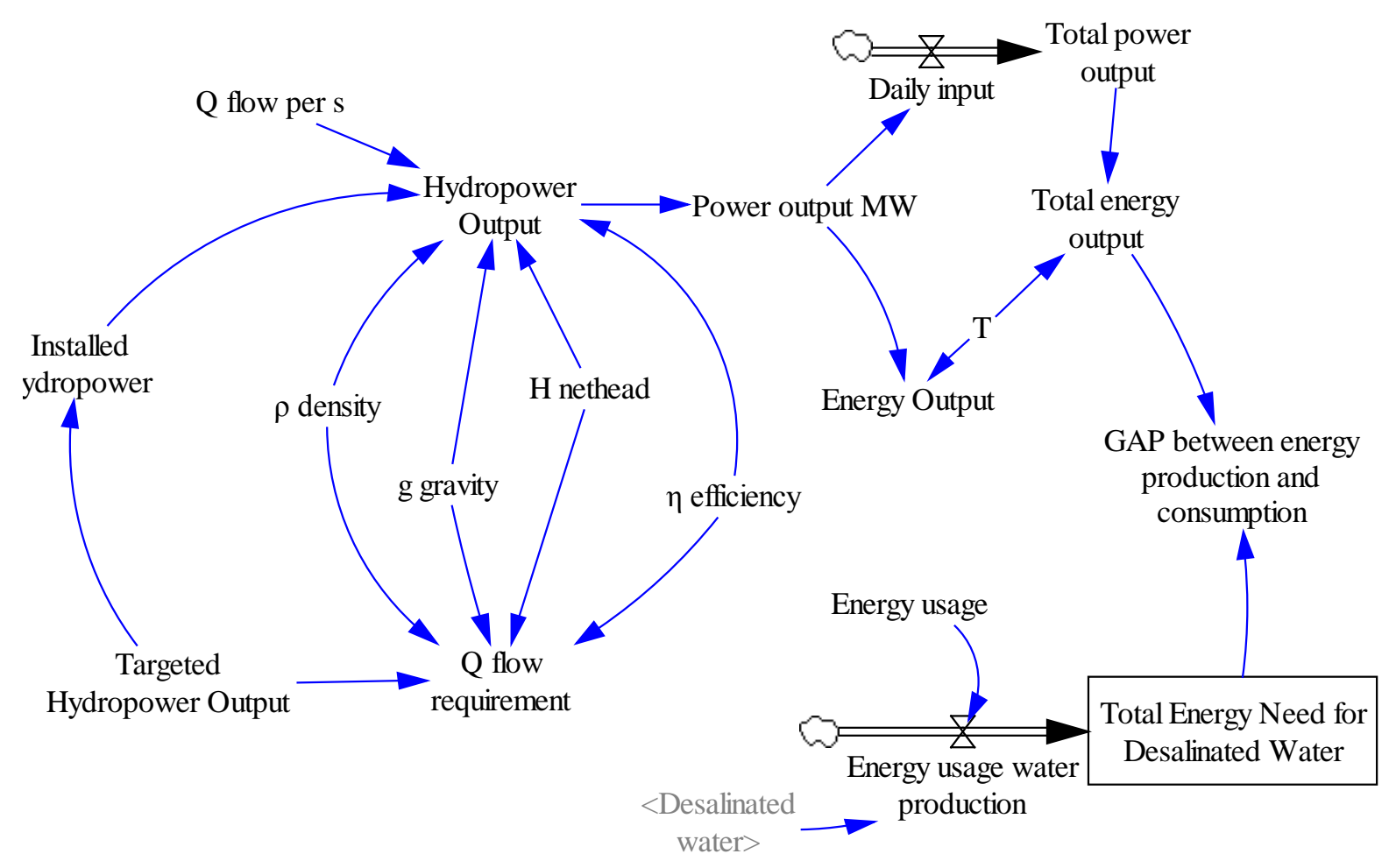

Fig. 2. A simplified System Dynamics diagram used to explore hydropower potential over a 25 year planning period 
As mentioned previously in section 3.1, the sub-models of the SDM are interconnected and changes in a variable in any sub-model affects the overall model (system). The maximum hydropower power output is entirely dependent on the availability of head and flow at the site. As shown in Fig. 3, flow rate $Q$ is dependent on water availability (Outflow) from the reservoir, which is a function of the Storage Level, the Daily demand, the Desalinated water supply, the Environmental flow (Eflow), the Evaporation and the Spill. The storage level is highly volatile due to fluctuations in inflow.

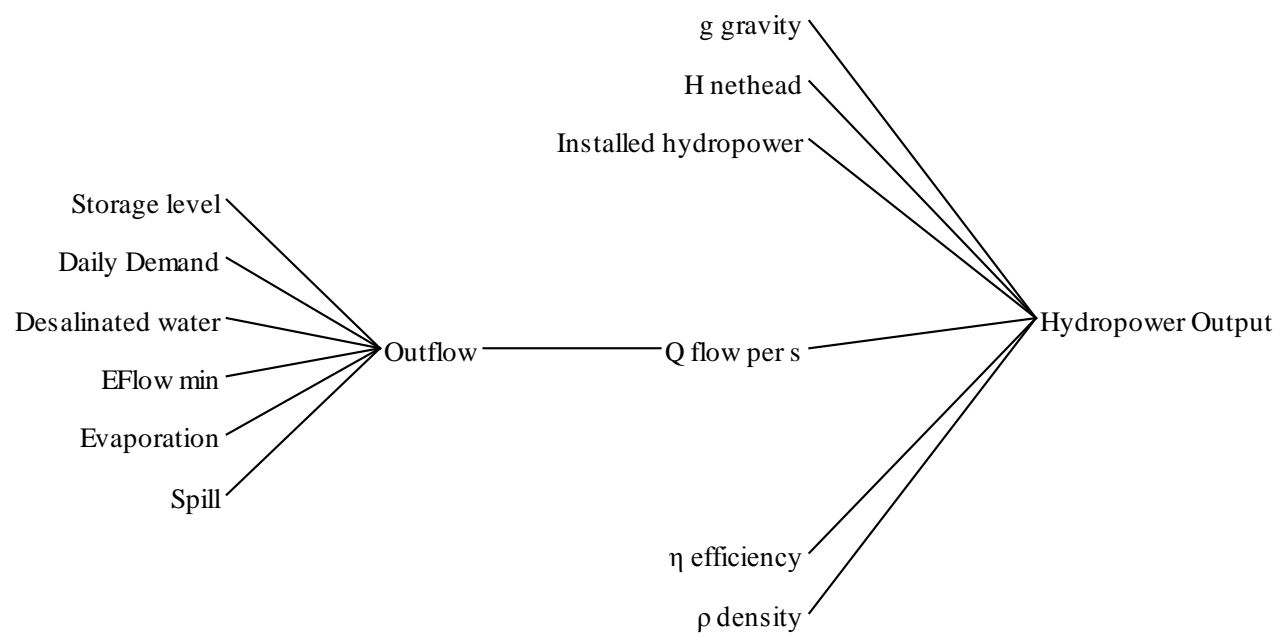

Fig. 3. Influence tree for flow rate $(Q)$ variable

Although the calculation procedure provides a straightforward method to predict the power potential, the estimation of parameters for duration and volume of the flow poses a real challenge. To overcome this challenge, the flow volume and duration data, based on 53 years of record (1961-2011), was created. This 53 year period covers wet, dry, normal and extreme hydrological years (e.g.: millennium drought between 1997 and 2009 experienced across Australia). As explained in section 3.2, use of the historical data as the input values for SDM provided a realistic foundation representing the randomness of weather pattern and extreme conditions (drought and flooding) for computing power production.

The interdependence of a system's components, which exists in the real world, is a key constituent of simulation. The idea of interdependencies goes beyond competition of power production to include the impact of randomness of weather patterns influencing inflow, demand for water, evaporation, population increase over time, and other key issues. One of the advantages of using simulation rather than a post-hoc manual analysis for certain output 
variables (e.g. spreadsheets) is that SDM allows for the randomness and interdependence to be concurrently considered. Further, SDM simulation allows for a large number of scenarios to be completed and compared simultaneously. This permits the user to quickly understand how the system would perform under extreme conditions if system constraints were eliminated. Whereas, post-hoc spreadsheet based computation by manipulating cells and formulas can be time consuming and does not allow users to pinpoint key predictor variables and sources of problems.

\section{Results}

\subsection{Flood risk mitigation}

The options modelled entail either raising the dam wall by $+15 \mathrm{~m}$ or $+23 \mathrm{~m}$ or lowering the dam wall by $-5 \mathrm{~m}$ or $-12 \mathrm{~m}$. The results show that that by operating the desalination plant and lowering the full storage level, additional flood mitigation can be bought more cheaply than by raising the dam wall, which offers a higher level of flood protection at higher cost. The results contrast high cost options that require the capital intensive raising of the Warragamba dam wall by $+15 \mathrm{~m}$ or $+23 \mathrm{~m}$ in order to provide "airspace" for potential flood mitigation with two lower cost options that involve lowering the FSL in the dam by $-5 \mathrm{~m}$ or $-12 \mathrm{~m}$ to provide potential flood mitigation. These latter options obviously reduce the current supply capacity of the dam and thus have an influence on the storages ability to provide water security. The results show that under the scenario modelled, that is, a repeat of the last 25 years of inflows but taking into consideration projected population growth that under the Business as Usual (BAU) scenario there are likely to be numerous flooding events ranging from minor to severe. These flood events have the potential to cause billions of dollars of damage, lost income and potentially some loss of life. Considering the future planned land development downstream from the dam there needs to be reasonably urgent consideration for improving the current flood mitigation capacity of the Warragamba dam. As raising the dam wall will be logistically challenging, reducing the FSL should be considered a viable solution if a similar level of water security can be provided by changing the operating regime of the existing and future implemented desalination plants.

Surprisingly the $-12 \mathrm{~m}$ option, which has the lowest cost of the four, provides sufficient flood protection and water security. This is primarily because the currently adopted MWP triggers have been adjusted to accommodate the $40 \%$ loss in dam capacity and brought the need for construction of additional desalination plants (DSP 2 and DSP 3) forward slightly. This 
option shows that by adjusting the current MWP trigger levels, there can be greater optimisation of existing and new supply expansion infrastructure, which can achieve the dual objectives of mitigating flood risk while maintaining adequate water security for the region.

\subsection{Drought risk mitigation}

As discussed above, under the current MWP designated operating rules, existing desalination plants operate at maximum capacity when available dam storages fall below $70 \%$ and continue to do so until storages reach $80 \%$ [8]. However, it is not clear whether the MWP operating rules would provide effective water security under extreme conditions similar to that experienced during the Millennium drought.

To address these uncertainties resulting from changes in the human and natural environment (e.g. population growth, urban development, demand for water and its impacts), we carried out a sensitivity analysis to determine the variation in output of a model with respect to changes in the values of the model's input(s). This analysis was conducted by firstly applying the current MWP BAU rules (70/80 rules), and then using these findings to inform a first order uncertainty analysis.

Through sensitivity analysis, key model inputs were compared based on their relative contribution to model output variability and uncertainty (Fig. 4 and Fig. 5). Sensitivity analysis is useful to explore how sensitive the average storage level is to a change to a key variable (e.g. plant construction timing and size, operation rules of the infrastructure, etc.). Through sensitivity analysis, we examined the impact of key variables in the model by changing it within a reasonable range of values while keeping all other variables constant at their baseline value. Historical records of system data such as daily inflow, spillage, and daily demand are typically used as basis for model inputs. Future conditions such as population growth and changes in demand were altered to reflect conditions in the future may change.

Fig. 4 illustrates the impact of input data sensitivity on model output average storage level and shows confidence bounds for all the output values of average storage level. The red line in the graph represents the mean value at each point in time. The mean value is not the same as the median value (middle of the confidence region) or the base run. The confidence bounds are computed at each point in time by ordering and sampling all the simulation runs. Confidence bound $50 \%$ means that $25 \%$ of the simulation runs have a value bigger than the top of the confidence bound and the other $25 \%$ have a value lower than the bottom. The 
outer bounds of average storage level (100 \%) show maximum values of approximately 100 percent and minimum values of approximately 1 percent at the end of the simulation.

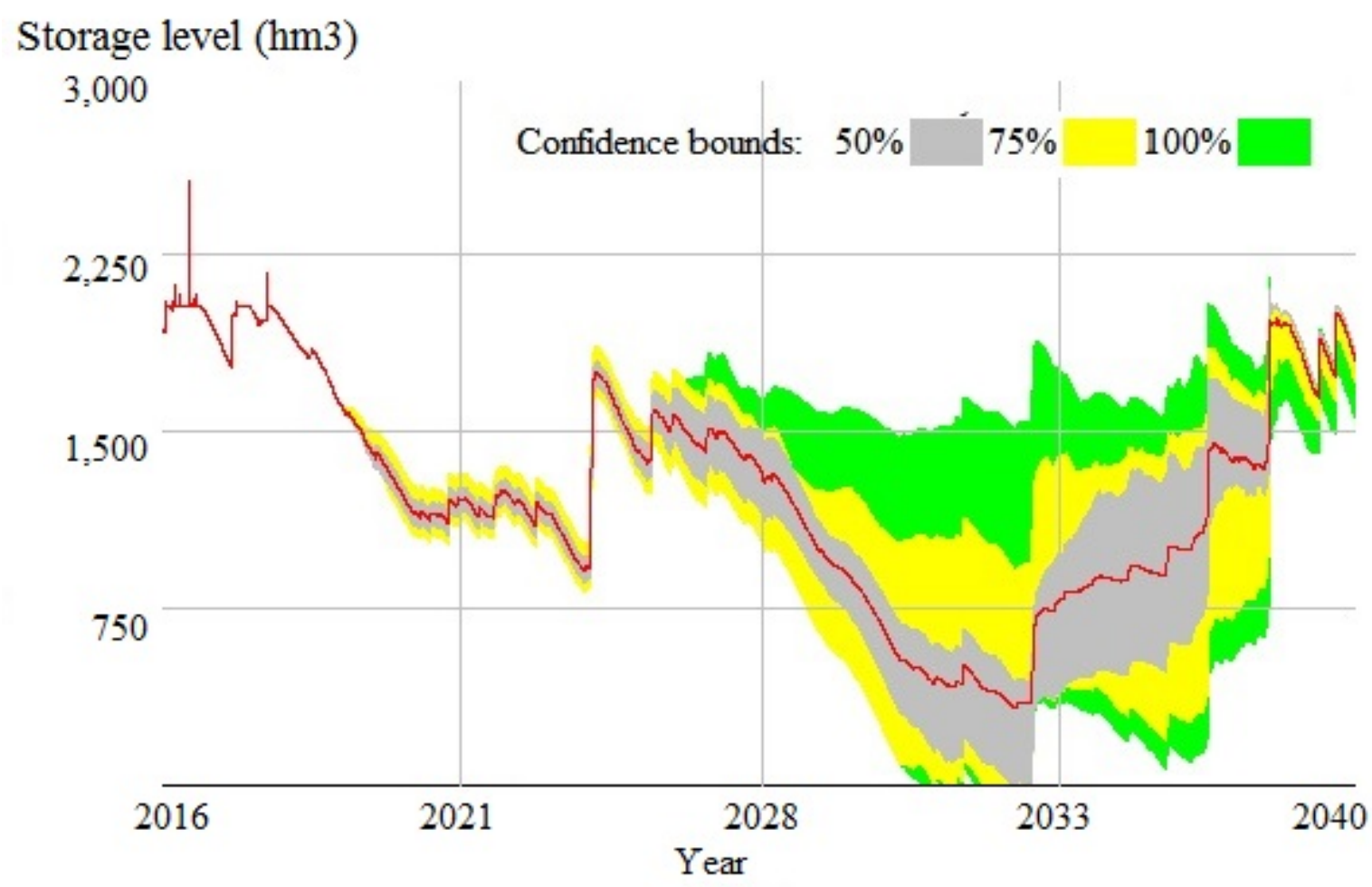

Fig. 4. Sensitivity graph showing confidence bounds for all the output values of Storage level that were generated when the three variables were varied

As illustrated in Fig. 5, 63 three scenarios (Table 3) were divided into three groups based on three plant sizes to provide a better comparison of these scenarios. Under each category, there were 21 scenarios tested to calculate the required total number new desalination plants, average storage level over a 25 year time period, number of years that the fleet of desalination plant will be utilised, and the number of years the storage level falls below a 40 percent threshold.

The dotted red line shows how often the storage level would fall below a $40 \%$ threshold for each scenario over a 25 year time frame. For example, this threshold will be exceeded only once under Scn61 within the first group of scenarios (Plant size 125,000 m²/d), with Scn28, the storage level will fall below 40 percent nine times over 25 years. Scn50 of the second group (Plant size 250,000 $\mathrm{m}^{3} / \mathrm{d}$ ) and Scn12 of the third group (Plant size 375,000 $\mathrm{m}^{3} / \mathrm{d}$ ) offered the best options within their own groups as the storage level would be kept above forty percent at all times. The worst scenario options in these two groups appeared to be Scn29 and Scn30, in which the threshold would be exceeded 8 and 6 times respectively. 


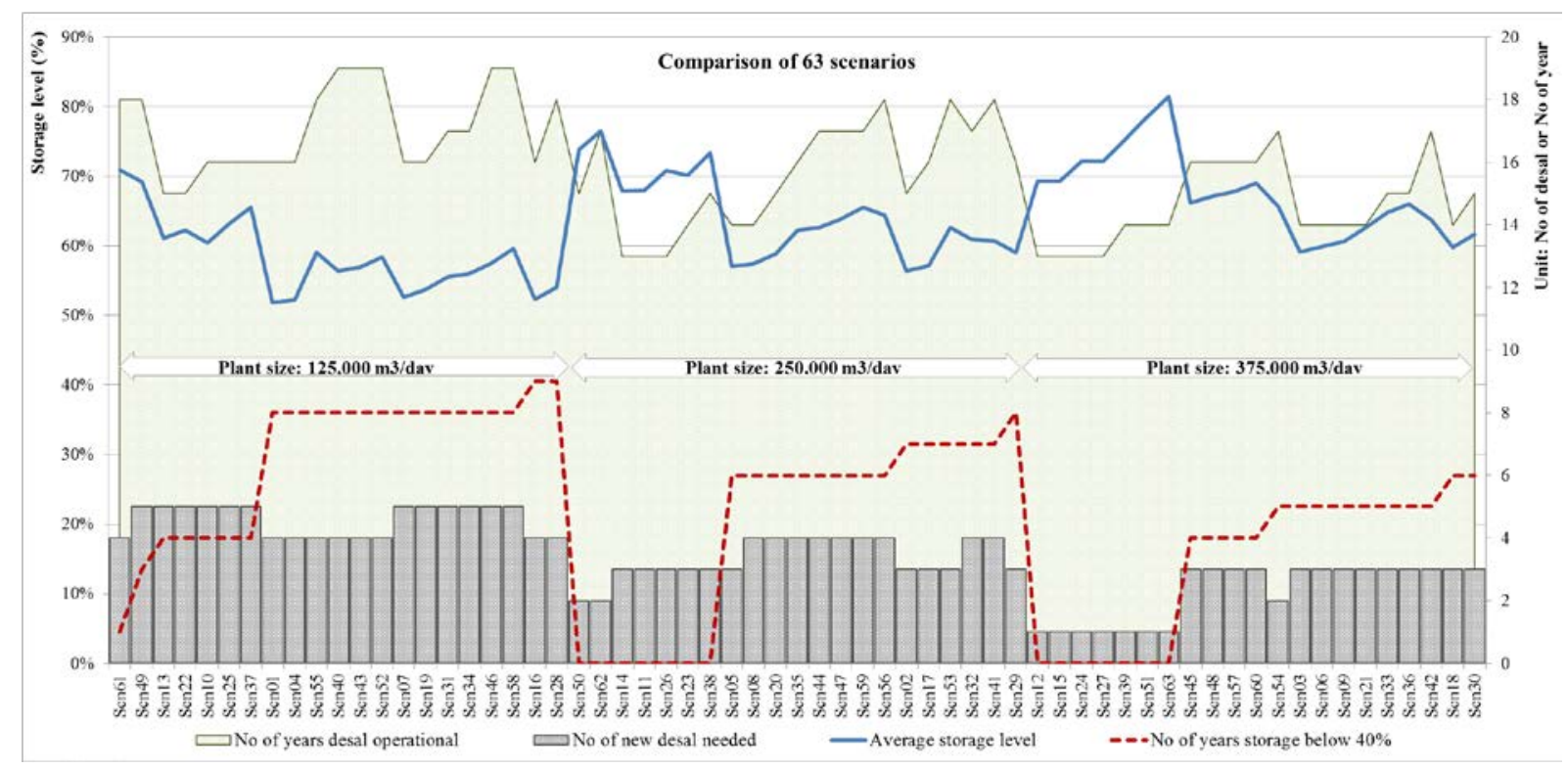

Fig. 5. Comparison of 63 scenarios in terms of three desalination plant capacities

Further analyses of these scenarios provide us a better picture of the water security, the infrastructure investment requirement and the operating frequency of these desalination infrastructures. Under the best scenario of the first group (Scn61), the water utility in Sydney would need four additional desalination plants with a 125,000 $\mathrm{m}^{3} / \mathrm{d}$ capacity over the next 25 year. And these new desalination plants will be operational for 18 out of 25 years maintaining a $71 \%$ average storage level over the 25 year modelling period while falling below $40 \%$ only once. On the other hand, the number of new desalinations under Scn50 and Scn12 would be 2 and 1 respectively. And these plants will be operational 15 years for Scn50 with a $74 \%$ average storage level (a 25 year average) and 13 years for Scn12 with a $69 \%$ average storage level (a 25 year average).

Based on these analyses, the Scn12 seems to be offering the best option followed by the Scn50 and the Scn61. However, to be able to complete a more informed decision on the best scenario, we compare the cost estimates of these scenarios in the following section.

\subsection{Optimisation of infrastructure investment decision}

Fig. 6 and Fig. 7 compare the best three scenarios in terms of investment timing and their costs. 


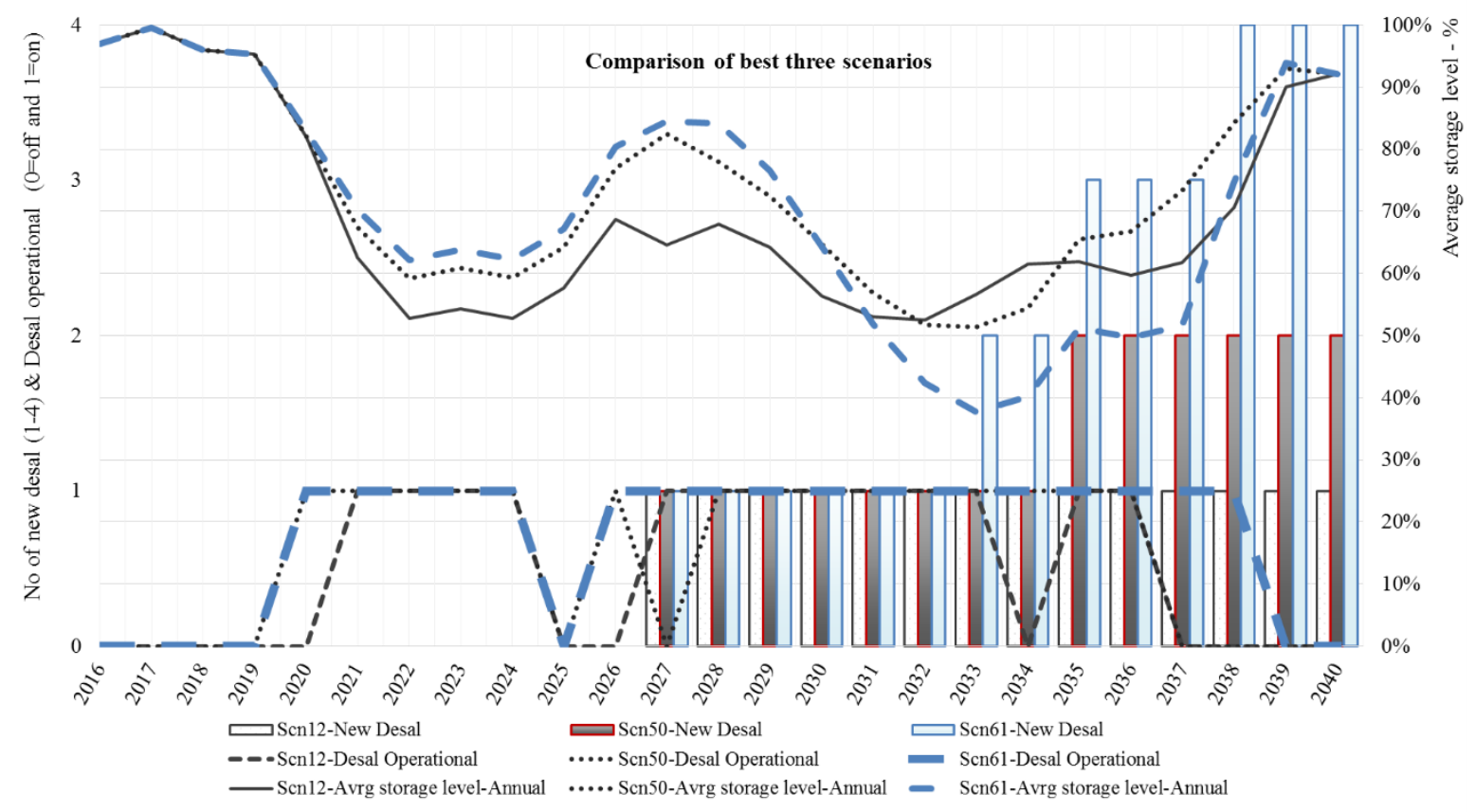

Fig. 6. Comparison of best three scenarios in terms of desalination operational frequency, need for additional desalination plants and average storage level

As shown in Fig.6, the time series analysis of these best scenarios (Scn12, Scn50 and Scn61) reveals the interactions and interrelationships between certain scenario variables. Table 4 describes the status quo assumptions for these three scenarios.

Comparison of three scenarios in terms of the cost of building new desalination plants shows that the costs, both capital and operating, are also sensitive to the timing and scale of the investment. This issue represents a choice between flexibility and scale [22]. Building a smaller scale plant has the advantage of not tying up large amounts of capital; however the trade-off is the loss of scale economies in constructing a large-scale plant [3].

Table 4. Baseline assumptions for Scn12, Sn50, and Scn61 scenarios

\begin{tabular}{llll}
\hline Parameter description & Scn12 & Scn50 & Scn61 \\
\hline Trigger level for Desalination start (\%) & 60 & 75 & 80 \\
Desalination plant size $\left(\mathrm{m}^{3} / \mathrm{d}\right)$ & 375,000 & 250,000 & 125,000 \\
Storage level for new desalination construction (\%) & 45 & 50 & 50 \\
\hline
\end{tabular}


As can be seen in Fig. 6 and Fig. 7, the first desalination plant will be needed in 2027 under all three scenarios. Under Scn12, one additional desalination plant will be adequate to augment supply to satisfy the demand for water.

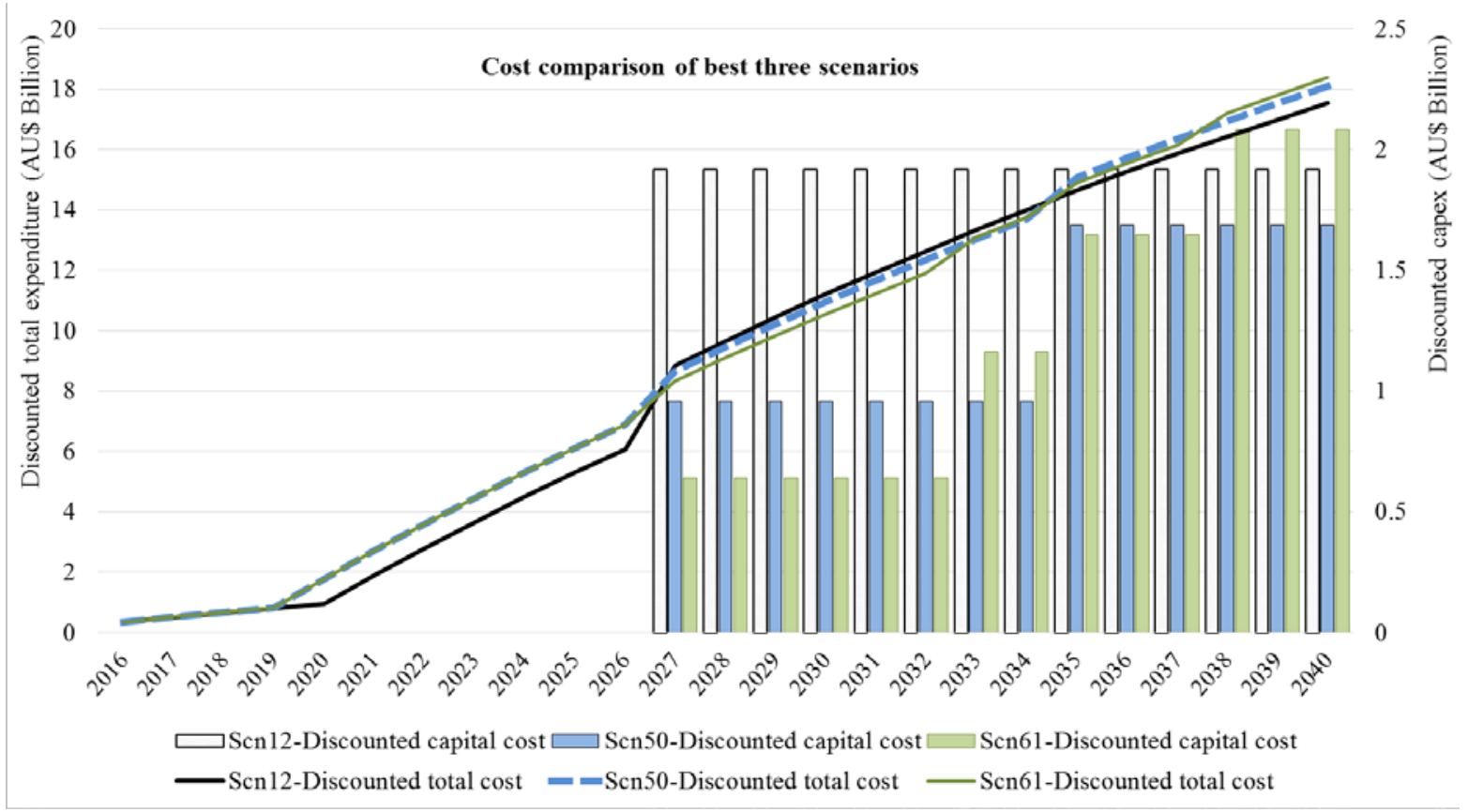

Fig. 7. Comparison of discounted total cost of building and operating new desalination plants

However, in order to meet increasing demand and counterbalance the reduced inflow during the dry years, the water utility in Sydney should build a second desalination plant in 2035 under Scn50, which brings the tally of desalination plants to two for this scenario. Under Scn61, a total of four desalination plants will be needed in 2027, 2033, 2035, and 2038 to meet the water requirements over the twenty five year period.

The simulation results show that the discounted cost of investment will be lowest if the desalination plant size is 250,000 m³ $/ \mathrm{d}$ (A $\$ 1.69$ B), followed by Scn12 (A\$1.92 B), and Scn61 (A\$2.08 B). However, the construction of smaller desalination capacity plants will increase the need for desalination to be operated more frequently (Fig. 3). Consequently, the operating costs of smaller size plants will be higher than for fleets of larger plants when considering longer planning life cycles. As shown in Fig. 5, the total discounted cost of Scn12 is estimated to be the lowest, followed by Scn50 and Scn61. 
Consistent with the findings of the previous section, the financial analysis further validated that Scn12 offered the most cost effective infrastructure investment strategy for addressing the dual water supply security and flood mitigation goals of the region.

As explained in previous sections, Scn12 offers best option in terms of additional infrastructure requirement (minimised investment), operational frequency of desalination plants (minimised energy usage), and the storage level (maximised water security). Therefore, the next section explores how Scn12 (i.e. the plant size 375,000 m3/d, the trigger level for starting desalination $=60 \%$, and the storage level threshold for initiating a new desalination construction $=45 \%$ ) can also result in the exploitation of renewable energy potential at Warragamba dam, by channelling additional spillage (due to lowering storage level and providing flood storage 'airspace') into an existing under-utilised hydroelectric power station located at the site.

\subsection{Exploiting renewable energy potential at Warragamba dam}

The Sydney desalination plant was constructed with the obligation to purchase a $100 \%$ renewable energy offset; namely the 67-turbine Capital Wind Farm at Bungendore. While this asset was originally purchased for offsetting the desalination plant energy requirements, it also has a wider role to increase the level of renewable energy supply to the energy portfolio of the growing of Sydney.

Interestingly, another under-utilised asset is the Warragamba hydroelectric power station with a single turbine with generation capacity of 50MW of electricity. Given that this hydroelectric plant has very constrained operational rules, and very little dam spillage under current dam operating conditions to be utilised effectively, it is rarely utilised. However, the optimised desalination planning scenario determined above (i.e. Scn12) opens up the opportunity to exploit this hydropower asset. Fig. 8 illustrates the SDM simulation results for the cumulative energy requirements for water desalination as well as the cumulative hydro electricity output from simulated discharge over a 25 year period.

Whilst the 2025 cumulative energy output of hydropower was estimated to be approximately $50 \%$ of the cumulative energy requirement for potable water desalination, by 2040 this fraction was estimated to have reduced to around $20 \%$ due to the increased requirements for desalination resulting from a growing population in Sydney.

It should be noted that the simulation results are based on assumptions that all of the water flowing through the hydropower plant can be converted to electrical energy and that the head 
is constant at facilities. The efficient and profitable utilisation of this existing hydro plant would be increased if the design and operating plan was modified to enable it to utilise excess water to meet peak demand periods in Sydney. Given that wholesale market prices for power provided during period periods is significantly higher than baseload wholesale rates, there is strong potential to generate strong revenues to partially offset any additional costs of operating the desalination plant to meet water security needs.

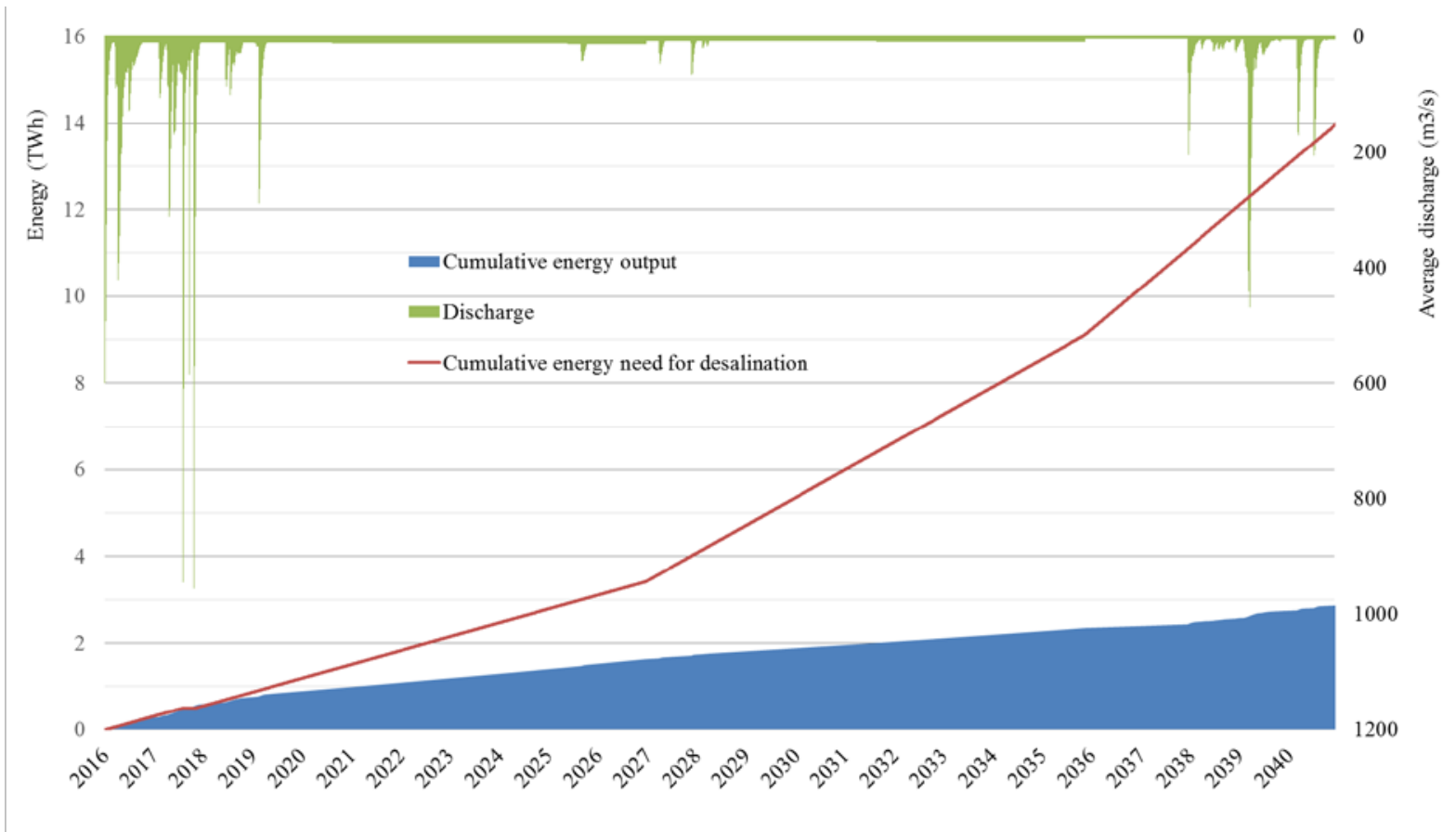

Fig.8. Simulation results for the cumulative energy need for water desalination and cumulative hydro electricity output from simulated discharge over a 25 year period

Developing the connection of the hydro power generation at Warragamba to the national grid and employing sophisticated short-term power trading software creates an opportunity to sell hydro power at commanding peak market prices, thereby ensuring a commercial income stream can be maintained. The data on price variation on the Sydney grid during times of stress reveals price variations of a high order with peak prices in the range of \$100-2070 AU \$/MWh in contrast to average prices of $40 \mathrm{AU}$ \$MWh [46]. Invariably, like speculation that is profitable, hydro power output should be negative (pumped storage) when prices are low, and positive (water released into turbines) when prices are high. 
In summary, this section demonstrates the additional benefit of greater renewable energy generation created for a scenario where the dam storage level is lowered from its current height to allow for flood storage retention requirements.

\section{Discussion}

For the first time, this paper empirically explored the concept of using rain-independent supply sources such as desalination as an integrated solution in a water supply grid of a major city in order to potentially defer or reduce the requirement for a capital investment in raising a dam wall for the purpose of providing additional flood mitigation 'airspace' that has become necessary for this expanding city, with housing now extending further into (hopefully) former flood plains. Maintaining an equivalent water security level for the city, through compensating a reduced dam storage level with a different regime for operating the cities' desalination capacity, also resulted in greater dam spillway releases that could be harnessed through an existing underutilised hydroelectric power plant located at Warragamba dam. This alternative water supply system planning scenario demonstrated that flood mitigation dam raising costs estimated between $\$ 500-\$ 800$ million dollars (AUD) could be deferred, while new capacity of renewable energy generation to support peak electricity demand in the densely populated Sydney could potentially be achieved. Given that the ongoing fixed cost availability charge of the Sydney desalination plant makes up around 75\% of the total annual lease cost when it is running at full capacity, there is a relatively marginal cost difference to utilise the plant more effectively through the scenario explored in this study. Overall, a viable scenario has been presented that achieves Sydney's interdependent goals of deferring capital intensive flood storage works, maintaining water security, better utilising existing desalination and hydropower assets, and increasing renewable energy generation can be achieved through applying systems thinking to a complex citywide water planning problem.

An SDM was utilised to demonstrate that an alternative set of policy (i.e. desalination plant construction and top-up trigger points, future plant size, hydropower generation, etc.) could mean that existing and future required desalination plants could be operated differently from current BAU in order to maintain sufficient water security for a major city (i.e. Sydney, Australia in this case) while also achieving the competing goal of mitigating flood risks to downstream residents. After all, flood protection airspace/storage can be provided by either lowering the dam FSL or raising the wall; the latter involves a costly construction investment. 
An advantage of rain-independent sources such as desalination or recycling plants is that they can offer continuous supply to a city in periods of low rainfall and ultimately reduce the rate of depletion of reservoir storages. In other words, increasing proportions of supply from desalination in a cities' portfolio of source options provides greater certainty that supply can meet demand in a city or region while also increasing community and real estate security in potential flood areas. The additional benefit of increased hydropower generation to satisfy peak electricity demand and downstream environmental flows are also evident.

This study showed that bulk water planning decisions for a city that is predominately reliant on surface water should consider desalination plants in a broader context than merely as supply sources that are utilised in drought conditions. In this study, our systems modelling and scenario analysis provided evidence that there is potential to cancel a capital intensive planned dam wall raising project for flood risk mitigation through reducing the capacity of the existing dam storage (e.g. $-12 \mathrm{~m}$ reduction in FSL) in order to provide a similar level of flood protection without extensive capital works costs. Through simple adjustments in the operating rules of the rain-independent desalination plants water security can be maintained at similar levels to BAU. Finally, economic analysis demonstrated that this alternative strategy has a lower discounted cost over the 25 year life cycle examined.

\section{Conclusion}

A main driver to conducting this study was to demonstrate that city- or region-wide water system planning needs to be considered systematically covering all causal relationships and water and water-related energy interactions, in order to best utilise sunken capital assets (e.g. infrequently utilised desalination plants) to maintain adequate water security while lower the long-term marginal cost of water supply. Major cities require integrated portfolios of bulk water supply sources including surface water, ground water, recycled water and desalinated water. However, often government departments and the bulk operators' water supply planners have predisposed views on the role of these supply sources in a city's water grid. This study demonstrates that contemporary water supply planning for major cities is complex and decisions often have unintended long-term consequences across economic, social, energy and environmental dimensions. Techniques such as Systems Modelling, as demonstrated herein, allows water planners systematically to explore a range of alternative planning decisions over medium to long-term periods and potentially reveal optimal decisions that would not be expected using current water planning paradigms. The study herein examines 
one major planning decision related to the provision of better flood protection for Sydney, Australia (i.e. dam raising or lowering for enhanced flood mitigation through desalination operating rules regime change). Water-energy interactions were also explored as part of the preferred planning scenario, and revealed that significant hydropower generation was also created.

The developed SDM can be utilised to explore a range of long-term planning scenarios surrounding the water supply and demand elements of this major city. Examples include considering alternative pricing scenarios to influence demand (e.g. temporary drought levy pricing), using existing supply sources under different operating rules (e.g. desalination plant operating rules), to name a few. Strategic water supply/demand planning options analysis enabled by such integrated tools such as SDM ensure that unintended planning consequences are identified, capital investments are optimised, and lateral thinking is encouraged in this industry.

\section{Acknowledgements}

This research is part of a study on desalinated water in Australian bulk water supply networks, funded by a grant from the National Centre of Excellence in Desalination Australia (NCEDA) to the Alfred Deakin Research Institute (ADRI) at Deakin University, in a project jointly managed with the Smart Water Research Centre at Griffith University, and with technical cooperation from AECOM Ltd.

\section{References}

[1] Hussey K, Pittock J. The Energy-Water Nexus: Managing the Links between Energy and Water for a Sustainable Future. Ecology and Society. 2012;17.

[2] Talebpour MR, Sahin O, Siems R, Stewart RA. Water and energy nexus of residential rainwater tanks at an end use level: Case of Australia. Energ Buildings. 2014;80:195-207.

[3] Dunstan C, Boronyak., L, Langham., E., Ison, N., Usher J., Cooper C. and White, S. . Think Small: The Australian Decentralised Energy Roadmap. CSIRO Intelligent Grid Research Program: Institute for Sustainable Futures, University of Technology Sydney; 2011. [4] Vieira AS, Beal CD, Stewart RA. Residential water heaters in Brisbane, Australia: Thinking beyond technology selection to enhance energy efficiency and level of service. Energ Buildings. 2014;82:222-36.

[5] Vieira AS, Stewart RA, Beal CD. Air source heat pump water heaters in residential buildings in Australia: Identification of key performance parameters. Energ Buildings. 2015;91:148-62.

[6] Vieira AS, Beal CD, Ghisi E, Stewart RA. Energy intensity of rainwater harvesting systems: A review. Renew Sust Energ Rev. 2014;34:225-42.

[7] Kenway SJ, Binks A, Lane J, Lant PA, Lam KL, Simms A. A systemic framework and analysis of urban water energy. Environ Modell Softw. 2015;73:272-85. 
[8] Schallenberg-Rodriguez J, Veza JM, Blanco-Marigorta A. Energy efficiency and desalination in the Canary Islands. Renew Sust Energ Rev. 2014;40:741-8.

[9] Siems R, Sahin O. Energy intensity of residential rainwater tank systems: exploring the economic and environmental impacts. J Clean Prod. 2015; In press.

[10] Retamal M, Glassmire J, Abeysuriya K, Turner A, White S. The Water-Energy Nexus: Investigation into the Energy Implications of Household Rainwater Systems. Sydney: Institute for Sustainable Futures, University of Technology; 2009.

[11] Mitchell C. Revolutionising how we think about infrastructure. ATSE Focus. 2014;187.

[12] Mo W, Wang R, Zimmerman JB. Energy-Water Nexus Analysis of Enhanced Water Supply Scenarios: A Regional Comparison of Tampa Bay, Florida, and San Diego, California. Environmental Science \& Technology. 2014;48:5883-91.

[13] Pittock J, Connell D. Australia Demonstrates the Planet's Future: Water and Climate in the Murray-Darling Basin. International Journal of Water Resources Development. 2010;26:561-78.

[14] Sahin O, Stewart RA, Porter MG. Water security through scarcity pricing and reverse osmosis: a system dynamics approach. J Clean Prod. 2015;88:160-71.

[15] NSW Office of Water. 2010 Metropolitan Water Plan. Sydney, NSW, AU: Department of Environment, Climate Change and Water; 2010.

[16] IPART. Review of water prices for Sydney Desalination Plant Pty Limited. In: Boxall PJ, Cox J, Krieger S, editors. Sydney NSW, AU: Independent Pricing and Regulatory Tribunal of New South Wales; 2012.

[17] Giurco DP, Turner A, Fane S, White SB. Desalination for Urban Water: Changing Perceptions and Future Scenarios in Australia. Chemical Engineering Transactions. 2014; 42.

[18] Productivity Commission. Australia’s Urban Water Sector, Report No. 55, Final Inquiry Report. Canberra, Australia 2011.

[19] ATSE. Sustainable Water Management: Securing Australia's future in a green economy - Report by the Australian Academy of Technological Sciences and Engineering (ATSE). Melbourne, Australia. 2012.

[20] SKM. Water Supply System Model and Yield Review 2009/2010. Prepared by SKM for Sydney Catchment Authority; 2011.

[21] CIE. Review of operating regime for Sydney water's desalination plant. Canberra ACT Australia: The Centre for International Economics; 2010.

[22] Helfer F, Lemckert C. The power of salinity gradients: An Australian example. Renew Sust Energ Rev. 2015;50:1-16.

[23] Kaunda CS, Kimambo CZ, Nielsen TK. Hydropower in the Context of Sustainable Energy Supply: A Review of Technologies and Challenges. ISRN Renewable Energy. 2012;2012:15.

[24] Carson L. The Australian Energy Resource Assessment - Second Edition. Canberra, Australia: Geoscience Australia 2014.

[25] Phillips MS, Peirson WL, Cox RJ. A Brief Appraisal of the Potential of Pumped Storage in New South Wales. UNSW Water Research Laboratory; 2013. p. 29.

[26] Ardizzon G, Cavazzini G, Pavesi G. A new generation of small hydro and pumpedhydro power plants: Advances and future challenges. Renew Sust Energ Rev. 2014;31:74661.

[27] SES. 2011. Warragamba Dam [Online]. NSW State Emergency Service,. Available: http://www.ses.nsw.gov.au/communitysafety/floodsafe/warragamba-dam [Accessed 5 November 2015. 
[28] Dedinec A, Taseska-Gjorgievska V, Markovska N, Pop-Jordanov J, Kanevce G, Goldstein G, et al. Low emissions development pathways of the Macedonian energy sector. Renewable and Sustainable Energy Reviews. 2016;53:1202-11.

[29] Loucks DP, van Beek E. Water resources systems planning and management : an introduction to methods, models and applications. Paris: Unesco; 2005.

[30] Porter MG, Downie D, Scarborough H, Sahin O, Stewart RA. Drought and Desalination: Melbourne water supply and development choices in the twenty-first century. Desalination and Water Treatment. 2014;55:2278-95.

[31] Sahin O, Siems RS, Stewart RA, Porter MG. Paradigm shift to enhanced water supply planning through augmented grids, scarcity pricing and adaptive factory water: A system dynamics approach. Environ Modell Softw. 2016;75:348-61.

[32] Scarborough H, Sahin O, Porter M, Stewart R. Long-term water supply planning in an Australian coastal city: Dams or desalination? Desalination. 2015;358:61-8.

[33] Roberts N. Introduction to computer simulation : the system dynamics approach. Reading, Mass.: Addison-Wesley; 1983.

[34] Ventana Systems. Vensim DSS. 6.0b ed. Harvard, MA: Ventana Systems, Inc.; 2012.

[35] Vennix JAM, Akkermans HA, Rouwette EAJA. Group model-building to facilitate organizational change: An exploratory study. Syst Dynam Rev. 1996;12:39-58.

[36] Van den Belt M, Dietz T, van den Belt M, ebrary Inc. Mediated modeling : a system dynamics approach to environmental consensus building. Washington, DC: Island press; 2004.

[37] Langsdale S, Beall A, Carmichael J, Cohen S, Forster C. Stacy Langsdale, Allyson Beall, Jeff Carmichael, Stewart Cohen, Craig Forster. Integrated Assessment Journal. 2007;7:51-79.

[38] NSW Government. 2015. 2014 NSW Population Projections data [Online]. Sydney, New South Wales, AU: The Department of Planning and Environment, NSW Government. Available: us/deliveringhomes/populationandhouseholdprojections/data.aspx 2015].

[39] Sydney Water. 2015. Water use in Sydney [Online]. Sydney, NSW, AU: Sydney Water. [Accessed April 2015.

[40] WaterNSW. 2015. Warragamba Dam - Facts and History [Online]. WaterNSW. Available: http://www.waternsw.com.au/supply/visit/warragamba-dam [Accessed 5 November 2015.

[41] Productivity Commission. Australia's Urban Water Sector. Canberra, Australia2011.

[42] Stewart R. Verifying the end use potable water savings from contemporary residential water supply schemes. Waterlines report. Canberra, Australia: National Water Commission; 2011.

[43] Scarborough H. Intergenerational equity and the social discount rate. Aust J Agr Resour Ec. 2011;55:145-58.

[44] Paish O. Small hydro power: technology and current status. Renewable and Sustainable Energy Reviews. 2002;6:537-56.

[45] Mishra MK, Khare N, Agrawal AB. Small hydro power in India: Current status and future perspectives. Renewable and Sustainable Energy Reviews. 2015;51:101-15.

[46] AEMO. Average Price Tables. Australian Energy Market Operator - AEMO; 2015. 